OPEN ACCESS

Edited by: Istvan Nagy, Imperial College London,

United Kingdom

Reviewed by:

Paul McCulloch,

Midwestern University, United States

Carlos Wilson

University Institute of Biomedical Sciences of Córdoba (IUCBC),

Argentina

Elizabeth Bradbury,

King's College London, United

Kingdom

${ }^{*}$ Correspondence:

Célia D. Cruz

ccruz@med.up.pt

Specialty section:

This article was submitted to Integrative Physiology,

a section of the journal

Frontiers in Physiology

Received: 11 March 2020

Accepted: 08 June 2020

Published: 07 July 2020

Citation:

Chambel SS, Tavares I and Cruz CD (2020) Chronic Pain After Spinal Cord Injury: Is There a Role for Neuron-Immune Dysregulation?

Front. Physiol. 11:748.

doi: 10.3389/fphys.2020.00748

\section{Chronic Pain After Spinal Cord Injury: Is There a Role for Neuron-Immune Dysregulation?}

\author{
Sílvia S. Chambel ${ }^{1,2}$, Isaura Tavares ${ }^{1,3}$ and Célia D. Cruz ${ }^{1,2 *}$ \\ ${ }^{1}$ Department of Biomedicine, Experimental Biology Unit, Faculty of Medicine, University of Porto, Porto, Portugal, \\ ${ }^{2}$ Translational NeuroUrology Group, Instituto de Investigação e Inovação em Saúde - i3S, Universidade do Porto, Porto, \\ Portugal, ${ }^{3}$ Pain Research Group, Instituto de Investigação e Inovação em Saúde - i3S, Universidade do Porto, Porto, \\ Portugal
}

Spinal cord injury (SCl) is a devastating event with a tremendous impact in the life of the affected individual and family. Traumatic injuries related to motor vehicle accidents, falls, sports, and violence are the most common causes. The majority of spinal lesions is incomplete and occurs at cervical levels of the cord, causing a disruption of several ascending and descending neuronal pathways. Additionally, many patients develop chronic pain and describe it as burning, stabbing, shooting, or shocking and often arising with no stimulus. Less frequently, people with $\mathrm{SCl}$ also experience pain out of context with the stimulus (e.g., light touch). While abolishment of the endogenous descending inhibitory circuits is a recognized cause for chronic pain, an increasing number of studies suggest that uncontrolled release of pro- and anti-inflammatory mediators by neurons, glial, and immune cells is also important in the emergence and maintenance of SCl-induced chronic pain. This constitutes the topic of the present mini-review, which will focus on the importance of neuro-immune dysregulation for pain after SCl.

Keywords: spinal cord injury, pain, glia, immune, astrocyte, microglia

\section{INTRODUCTION - SPINAL CORD INJURY}

Spinal cord injury (SCI) causes major disturbances in sensory, motor, and autonomic function, leading to permanent loss of function and strongly impacting the physical, psychological, and social well-being of patients and caregivers (Braaf et al., 2017). It is estimated that 27 million people live worldwide with life-long consequences of SCI (James et al., 2019). Loss of function reflects the spinal level of the injury, with a high prevalence of injuries at the cervical and thoracic segments; the type of injury (compression, laceration, contusion, or ischemic insult); and the extent of the damage (Silva et al., 2014). Although life expectancy has greatly increased due to improved medical care, patients' quality of life is severely compromised by several factors, including chronic pain (Yang et al., 2014; Kjell and Olson, 2016).

\section{CELLULAR ACTIVATION IN SCI AT THE LESION SITE}

Tissue remodeling begins immediately after SCI and continues for extended periods of time. SCIinduced alterations in the spinal cord occur in four steps (Rust and Kaiser, 2017). The (1) primary 
injury comprises the initial mechanical trauma (Rossignol et al., 2007). Within the first hours after injury, tissue damage initiates a series of destructive events that disrupt the spinal cord vasculature and blood-spinal cord barrier (BSCB). During secondary injury (2), platelets begin to invade the injury site and cause vasospasm, resulting in ischemia, glutamate release and oxidative stress (Park et al., 2004). The lesion extends and neuronal and glial cells undergo apoptosis and necrosis. Endogenous molecules, such as interleukin (IL)-1 $\alpha$, IL-33, ATP, and danger-associated molecular patterns (DAMPs) (Didangelos et al., 2016; Yang et al., 2017; Tran et al., 2018), are released by dying neurons and glial cells. This initiates a neuroinflammatory response, mediated by CNS astrocytes, microglia, and bloodborne neutrophils (Alizadeh et al., 2019).

Astrocytes are the first responders after a CNS injury (Pineau et al., 2010). Immediately after SCI, astrocytes become reactive (Xu et al., 1999; Bradbury and Burnside, 2019). Reactive astrocytes increase cytokine [e.g., IL-1 $\beta$, IL-6, IL-12, tumor necrosis factor alpha (TNF- $\alpha)$ and interferon gamma (IFN- $\gamma$ )] and chemokine (e.g., CCL2, CXCL1, and CXCL2) release in response to injury, which trigger recruitment of neutrophil and pro-inflammatory macrophages (Pineau et al., 2010; Alizadeh et al., 2019). Reactive astrocytes also release TGF- $\beta$ and IL-10 that harness inflammation and avoid spreading of apoptotic and necrotic cells (Alizadeh et al., 2019) (Table 1).

Neutrophils are the first immune cells to respond to SCI, peaking at 24 h post-injury (Dusart and Schwab, 1994) but mostly disappear following the acute inflammatory phase (Neirinckx et al., 2014). Neutrophils are most likely attracted by CXCL1 and leukotriene-B4 (LTB4) secreted at the injury site. Invading neutrophils release pro-inflammatory molecules that exacerbate astrocytes and microglia activation at the lesion (Perkins and Tracey, 2000; Schomberg and Olson, 2012) (Table 1).

CNS resident microglia polarize within 5-15 min in response to injury, extending their processes toward the injury site. Once activated, microglia assume an amoeboid shape, proliferate and migrate to the lesion site (Popovich and Hickey, 2001; Sroga et al., 2003). There they play a crucial role in clearing cellular debris and aiding in wound sealing and glial scar maturation (Vilhardt, 2005; Loane and Byrnes, 2010). Microglia also express receptors to DAMPs released by injured neurons (Block et al., 2007; Loane and Byrnes, 2010). They are also responsible for releasing TNF$\alpha$, IL-1 $\beta$, and C1q, which induce the activation of a subtype of astrocytes responsible for neuronal and oligodendrocyte cell death (Liddelow et al., 2017), an event linked to the emergence of neuropathic pain (Table 1).

While SCI-related microglial activation used to be perceived as an exclusively harmful event, it is now recognized that microglia also exert a neuroprotective role. Studies have shown cavity enlargement after early microglia ablation following SCI (Hines et al., 2009). More recently, using a $C \times 3 c r 1^{\text {creER }}$ mouse model, researchers demonstrated that eliminating microglia results in enhanced glial scar formation and neuronal and oligodendrocyte death, accompanied by poor locomotor performance (Bellver-Landete et al., 2019).

Twenty-four hours post-injury, circulating monocytes are recruited to the site of injury, where they differentiate into macrophages. Macrophages can be broadly divided into proinflammatory M1 or anti-inflammatory M2 macrophages. M1 macrophages are activated via toll-like receptors (TLRs) and IFN$\gamma$, upregulating the expression of pro-inflammatory cytokines such as IL-6, IL-1 $\beta$, IL-12, and TNF- $\alpha$, and causing axonal retraction. Conversely, the M2 phenotype is activated by IL13 or IL-4 (Gensel and Zhang, 2015). The shift from M1 to M2 macrophages is known to contribute to tissue healing (Deonarine et al., 2007; Nahrendorf et al., 2007) but does not occur, or is strongly impaired, in the lesioned spinal tissue (Kigerl et al., 2009). Kigerl et al. (2009) have demonstrated that, in a mouse model of midthoracic spinal contusion, M1 macrophage turnover is exacerbated in response to SCI, dominating the lesion site and nearby spared tissue, while M2 macrophages are short-lived, dissipating within 3-7 days post-SCI (Table 1).

Adaptive immune response also plays an important role in inflammatory response after SCI. After being activated in the spleen and bone marrow within $24 \mathrm{~h}$ post-SCI, $\mathrm{T}$ - and $B$-lymphocytes infiltrate the injured spinal cord, their numbers peaking at 7 days post-injury and remaining elevated in chronic stages of disease (Sroga et al., 2003; Jones, 2014). Activated T cells are particularly important on the modulation of inflammation following SCI as they can affect neuronal and glial survival via release of pro-inflammatory cytokines and chemokines (Jones, 2014), thus impairing recovery following SCI. Further information on the role of lymphocytes following SCI can be found elsewhere (Jones, 2014; Noble et al., 2018) (Table 1).

The third step comprises (3) formation and maturation of the glial scar by activated astrocytes. Recent studies revealed that microglia are also important players in glial scar formation, by accumulating around the scar and modulating astrocyte proliferation during scar formation via insulin-like growth factor 1 (IGF-1) (Bellver-Landete et al., 2019). Moreover, Zhou et al. (2020) have also demonstrated that microglia form a concentric physical barrier between the center of the lesion and its border, promoting wound compaction and recovery.

The final step in spinal cord remodeling after SCI consists of restricted (4) structural tissue regeneration occurring in the weeks and months after SCI (Shechter and Schwartz, 2013; Rust and Kaiser, 2017). However, the environment surrounding the scar is highly inhibitory axonal regrowth and reconnection. Thus, recovery of function is rarely achieved after a CNS injury, prompting the emergence of subsequent pathologies, including chronic neuropathic pain.

\section{PAIN}

Pain is defined by the International Association for the Study of Pain (IASP) as an unpleasant sensory and emotional experience, associated with actual or potential tissue damage, or described in terms of such damage (Loeser and Treede, 2008). While acute pain is usually well managed by patients and clinicians and resolved within a short period of time, chronic pain loses its protective role and becomes a disease in itself, even after resolving the triggering cause. 
TABLE 1 | Innate and adaptive cells involved in the release of immune molecules at the injury site following spinal cord injury.

\begin{tabular}{|c|c|c|c|c|}
\hline & Type of cell & Function at the injury site & $\begin{array}{l}\text { Pro-inflammatory } \\
\text { molecules released } \\
\text { at the injury site }\end{array}$ & $\begin{array}{l}\text { Anti-inflammatory } \\
\text { molecules released } \\
\text { at the injury site }\end{array}$ \\
\hline \multirow[t]{4}{*}{ Innate immune cells } & Astrocytes & $\begin{array}{l}\text { - Switch from quiescent to reactive } \\
\text { following SCI } \\
\text { - Recruit neutrophils and } \\
\text { M1-macrophages } \\
\text { - Involved in glial scar formation }\end{array}$ & $\begin{array}{l}\text { IL-1 } \beta, \text { IL-6, IL-12, } \\
\text { TNF- } \alpha, \text { IFN- } \gamma, \text { TGF- } \beta \\
\text { CCL2, CXCL1, CXCL2 }\end{array}$ & TGF- $\beta, I L-10$ \\
\hline & Microglia & $\begin{array}{l}\text { - Clear cellular debris from neuronal } \\
\text { and glial cell apoptosis } \\
\text { - Aid in wound sealing }\end{array}$ & $\begin{array}{l}\text { IL-1 } 1 \beta, \text { IL-2, IL-6, IL-12, } \\
\text { IL-18, TNF- } \alpha, \text { IFN- } \gamma \\
\text { C1q NO, ROS }\end{array}$ & TGF- $\beta$, IL-10, IGF-1 \\
\hline & Neutrof & $\begin{array}{l}\text { - Attracted by CXCL1 and LTB4 } \\
\text { - Clear debris from the injury site } \\
\text { - Recruit monocytes/macrophages }\end{array}$ & $\begin{array}{l}\text { IL-1 } \beta, \text { IL-8, IL-12, } \\
\text { TNF- } \alpha, \text { IFN- } \gamma \text { MPO, } \\
\text { MMP-9 }\end{array}$ & Unknown \\
\hline & $\begin{array}{l}\text { Monocytes } \\
\text { Macrophages }\end{array}$ & - Polarization from M1-M2 subtypes & $\begin{array}{l}\mathrm{IL}-1 \beta, \mathrm{IL}-6, \mathrm{IL}-12, \mathrm{IL}-18 \\
\mathrm{TNF}-\alpha, \mathrm{IFN}-\gamma \mathrm{NO}, \mathrm{ROS}\end{array}$ & IL-10, TGF- $\beta$ \\
\hline \multirow[t]{2}{*}{ Adaptive immune cells } & T-lymphocytes & $\begin{array}{l}\text { - Promote CNS fibrosis and } \\
\text { autoimmunity }\end{array}$ & $\begin{array}{l}\text { IL-1 } \beta, \text { IL-12, TNF- } \alpha \\
\text { CCL2, CCL5, CXCL10 }\end{array}$ & $\begin{array}{l}\text { IL-2, IL-4, IL-5, IL-6, } \\
\text { TGF- } \beta\end{array}$ \\
\hline & B-lymphocytes & $\begin{array}{l}\text { - Promote autoimmunity and } \\
\text { demyelination }\end{array}$ & Unknown & Unknown \\
\hline
\end{tabular}

Pain perception is often initiated by the activation of nociceptors by noxious chemical, mechanical, or thermal stimuli in the periphery. These sensory neurons fall into two categories: medium-sized myelinated $\mathrm{A} \delta$ fibers and smalldiameter, unmyelinated C-fibers. In the spinal cord, they synapse with relaying second-order neurons (either specific nociceptive neurons (NS) or wide-dynamic range neurons (WDR) or with inhibitory/excitatory spinal interneurons. Axons originated in these spinal cord neurons transmit ascending input to several supraspinal areas, namely the brainstem areas and the thalamus, the latter of which relays nociceptive information to cortical areas (Fenton et al., 2015; Boadas-Vaello et al., 2016). Nociceptive input is then processed and perceived, resulting in the activation of top-down descending modulation. These pathways may recruit higher brain centers, such as the prefrontal cortex and the amygdala, linked to cognitive and emotional aspects of pain. Top-down modulation also involves several supraspinal nuclei, including a midline relay circuit centered at the periaqueductal gray and rostral ventromedial medulla (PAG-RVM) (Heinricher et al., 2009; Boadas-Vaello et al., 2016). This key PAG-RVM circuit is connected with several brainstem regions, such as the locus coeruleus, the caudal ventrolateral medulla (VLM), and the dorsal reticular nucleus (DRt). The VLM and the DRt are reciprocally linked with the spinal cord, in circuits that may decrease or increase nociceptive information (Martins and Tavares, 2017). Descending pathways operate via release of serotonin, norepinephrine, and dopamine at supraspinal and spinal levels (Bourne et al., 2014). Considering the complexity of ascending and descending nociceptive neurotransmission, described in detail elsewhere (Boadas-Vaello et al., 2016; Martins and Tavares, 2017), it comes as no surprise that SCI strongly compromises these circuits and jeopardizes endogenous pain control circuits.

\section{Pain Following Spinal Cord Injury}

Pain arising after SCI has life-long consequences, strongly impairing patients' quality of life and often exceeding the impact of other functional disabilities. Pain manifests itself in several ways after SCI. While acute pain accompanies the injury and the recovery period, receding with tissue scarring, chronic pain emerges due to maladaptive neuroplasticity. More than $50 \%$ of SCI patients report chronic pain within a year of spinal lesion (Dijkers et al., 2009; Finnerup, 2013; Burke et al., 2017). Gabapentin, opioids and pregabalin remain gold standard for SCI-associated pain treatment, but are often ineffective and do not prevent pain worsening (Widerström-Noga, 2017).

Classically, SCI-related chronic pain can be divided into three major groups: nociceptive, neuropathic, or other/unknown pain (Bryce et al., 2012). Nociceptive SCI-derived pain includes musculoskeletal and visceral pain (Bryce et al., 2012; Shiao and Lee-Kubli, 2018). Neuropathic pain reflects SCI-induced 
damages in the somatosensory system and is divided into atlevel, below-level, and above-level neuropathic pain. At-level pain usually emerges at early time points after SCI. It refers to pain felt in the dermatomes at the level of injury and includes central and peripheral components. Below-level pain is typically of central origin, felt diffusely below the level of injury and appearing when chronicity has set (Siddall et al., 2003; Finnerup, 2013). Finally, above-level neuropathic pain is now described as "other neuropathic pain" (Finnerup, 2013), relating to injury management, such as wheelchair pulling or pain following surgery.

\section{Neuropathic Pain Emergence Following Peripheral Nerve Injury}

Spatial and temporal activation of glial cells in the spinal cord in several animal models of peripheral nerve injury has been vastly studied, but fewer data are available regarding SCIinduced neuropathic pain. This surely reflects the difficulties of reporting pain levels in animals with impaired mobility, as classical tests evaluate evoked responses to peripheral stimuli (Silva et al., 2014; Kramer et al., 2017). Therefore, much of our present knowledge on SCI-induced neuropathic pain stems from studies using models of peripheral nerve injury. Early studies in peripheral neuropathic pain reported increased GFAP immunostaining, an established marker for astrocytes, in the spinal dorsal horn (SDH) that correlated with emergence of hyperalgesia after sciatic nerve constriction injury (Garrison et al., 1991). Wagner and Myers demonstrated the role of TNF- $\alpha$ in hyperalgesia arising after sciatic nerve compression (Wagner and Myers, 1996), which has been proved to induce activity in primary nociceptors, hyperalgesia, and inflammation in rats (Sorkin et al., 1997; Junger and Sorkin, 2000), a process resulting from glial activation (Colburn et al., 1999; Zhuang et al., 2005). Macrophages are also involved in the emergence of neuropathic pain in models of peripheral nerve injury. Blockade of macrophage-colony stimulating factor signaling in a mouse model of partial sciatic nerve ligation prevented the development of injury-associated neuropathic pain (Lee et al., 2018). Further data on the role of neuroimmune interactions in peripheral nerve injury models can be found elsewhere (Malcangio, 2019; Tozaki-Saitoh and Tsuda, 2019).

\section{Neuropathic Pain Emergence Following Spinal Injury \\ The Role of Microglia and Astrocytes}

Fewer studies have focused on the contribution of immune and glial cells to the emergence of neuropathic pain after SCI. Early studies by Peng et al. (2006) have demonstrated that a T13 unilateral hemisection produces bilateral microglia activation and TNF- $\alpha$ expression below the lesion level, correlating with hindpaw mechanical allodynia in SCI rats. Treating a T13 rat hemisection with etanercept, a TNF- $\alpha$ blocker, resulted in decreased mechanical allodynia and microglial activation. Treatment with minocycline, a microglial inhibitor, also improved pain-associated behaviors, demonstrating that TNF- $\alpha$ is critical in the establishment of neuropathic pain after
SCI and dependent on microglial activation (Marchand et al., 2009). Thoracic spinal contusion also causes chronic activation of microglia as far as the lumbar spinal cord (Hains et al., 2003; Zai and Wrathall, 2005). When microglia activation is reversed by intrathecal administration of minocycline, lumbar SDH neurons hyperexcitability and pain-related behaviors decrease (Hains and Waxman, 2006; Tan et al., 2009). Early intrathecal administration of carbenoxolone, a gap junction decoupler, to T13 hemisected rats prevents astrocyte activation distant from the injury site and attenuates the development of thermal hyperalgesia and mechanical allodynia (Roh et al., 2010). Intrathecal administration of propentofylline (PPF), that prevents astrocytic and microglial activation and regulates the release of pro-inflammatory cytokines (Raghavendra et al., 2003; Arriagada et al., 2007), after a T13 transverse hemisection attenuates the development of mechanical allodynia and thermal hyperalgesia in the rat. Additionally, PPF reduces astrocyte and microglia activation away from the lesion site, thus decreasing hyperexcitability of lumbar WDR neurons and reducing belowlevel neuropathic pain in the rat (Gwak et al., 2008; Gwak and Hulsebosch, 2009).

At-level central neuropathic pain depends on p38-MAPK signaling. Following a thoracic contusion injury, p3 $8 \alpha-\mathrm{MAPK}$ is activated in neurons and microglia, but not in astrocytes, contributing to neuronal hyperexcitability (Crown et al., 2006, 2008; Gwak et al., 2009). Several other studies have identified microglial and astrocytic activation as key events for the development of below-level neuropathic pain (Detloff et al., 2008; Carlton et al., 2009; Gwak et al., 2012).

\section{The Role of Immune Mediators}

Following a SCI, interactions between nociceptive neurons, SDH neurons and glial cells are severely altered. After SCI, nociceptors become hyperactive and, upon stimulation, secrete increased amounts of glial modulators such as ATP, colonystimulating factor-1 (CSF1), chemokines or caspase-6 (CASP6) (Ji et al., 2016). These molecules activate spinal microglia in the $\mathrm{SDH}$, which respond by increasing the expression ATP and CX3CL1 receptors. Microglial cells increase secretion of TNF- $\alpha$ and IL-1 $\beta$, responsible for enhancing excitatory and suppressing inhibitory synaptic transmissions in spinal cord lamina II neurons (Kawasaki et al., 2008). In the SDH, activated astrocytes are also able to potentiate excitatory synaptic transmission Nerve growth factor (NGF) release, which facilitates nociceptive neurotransmission, leads to neuropathic pain (Chen et al., 2014). In addition, NGF, which is also produced by infiltrating immune cells, may induce spinal expansion of the central terminals of nociceptors, amplifying synaptic input and further contributing to central neuropathic pain (Stroman et al., 2016; Gwak et al., 2017). SCI-induced dysregulation of neuronglia crosstalk is not restricted to the spinal cord but has also been reported within dorsal root ganglia (DRG), affecting the interaction between Schwann cells within DRG neurons (Lee-Kubli et al., 2016) (Figure 1).

Chemokines are vital players in neuropathic pain development and maintenance following peripheral nerve injury (Zhang et al., 2017). They are likely involved in the 


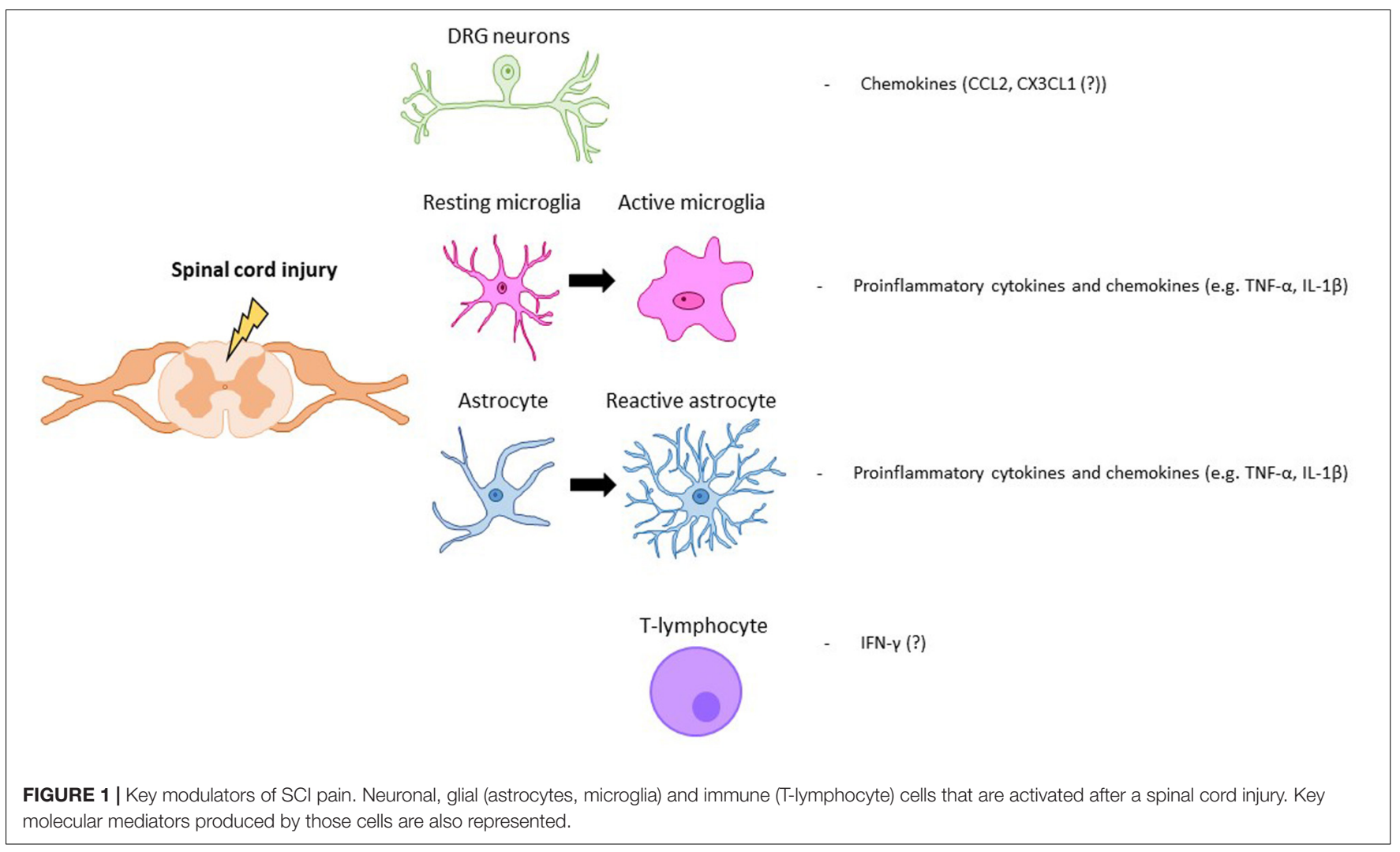

mechanism of SCI-induced chronic neuropathic pain but the number of studies using SCI models to detail the contribution of specific chemokines is lacking.

\section{The Role of Neurons}

SCI-induced neuropathic pain also reflects neuronal hyperexcitability and increased spontaneous activity, observed both in DRG and spinal neurons, associated with behavioral responses to mechanical and thermal stimuli. This is concomitant with persistently activated microglia and astrocytes in $\mathrm{SDH}$ segments distant from the lesion site, the primary target of pro-inflammatory mediators released by those cells (Bedi et al., 2010). Therefore, there has been interest in developing strategies to control and reduce neuronal hyperexcitability, particularly at the spinal level. In a recent rodent SCI study, mouse cortical GABAergic interneurons, derived from the embryonic medial ganglionic eminence (MGE), have been transplanted into the spinal cord. This has resulted in a reduction in hyperexcitability associated with neuropathic pain (Braz et al., 2017). Efforts to translate these preclinical transplantation studies to the clinic are still ongoing.

\section{CLINICAL TRIALS ON SCI-ASSOCIATED PAIN}

Neuroimmune interactions on pain emergence after SCI are still rarely addressed on clinical trials. Kwon et al. (2009) found increased levels of TNF- $\alpha$ receptor 1 in cerebrospinal fluid (CSF), which correlated with the emergence of neuropathic pain. A phase II trial on the effects of minocycline administration after traumatic SCI revealed, at 1-year follow-up, improved motor recovery but effects on pain improvement were not fully satisfactory (Casha et al., 2012; Badhiwala et al., 2018b).

\section{DISCUSSION AND CONCLUSION}

Alleviation of neuropathic pain arising after SCI is still an unmet need for most SCI patients. Current pharmacological pain treatments are unsatisfactory and there is an urgent need to develop more effective strategies. Therefore, neuroimmune dysregulation in the context of CNS injuries has emerged as a putative target for improved treatment of SCI-induced neuropathic pain. Accumulating evidence supports a role for neuro-immune dysregulation, often reflecting altered crosstalk between neurons, activated glial cells and invading immune cells (macrophages and T-cells). Dysregulation occurs as a consequence of the inflammatory response to SCI. This response is necessary in the early post-SCI stages to close the injury site but the resulting scar prevents full tissue regeneration and leads to maladaptive neuroplasticity and chronic pain. The challenge is, therefore, to control the inflammatory response and promote tissue repair, both at a structural and functional levels. Presently, methylprednisolone, a potent anti-inflammatory 
drug, is the only medication in clinical practice used to treat SCI in early stages. Methylprednisolone has a widespread activity and is able to reduce cytokine release (Ulndreaj et al., 2016) but reported side effects, and lack of positive outcomes in pain control, among other chronic problems, has led investigators to question its use (Evaniew et al., 2016; Monteiro et al., 2018). The identification of glial cells as important sources of pro- and anti-inflammatory neuromodulators allowed the identification of carbenoxolone, minocycline, and PPF as eventual therapeutic tools (Shultz and Zhong, 2017; Badhiwala et al., 2018a). Although these drugs have produced interesting results in pre-clinical and early clinical trials, dosages and timing for intervention need to be critically defined in the future for effective pain management.

\section{REFERENCES}

Alizadeh, A., Dyck, S. M., and Karimi-Abdolrezaee, S. (2019). Traumatic spinal cord injury: an overview of pathophysiology, models and acute injury mechanisms. Front. Neurol. 10:282. doi: 10.3389/fneur.2019.00282

Arriagada, O., Constandil, L., Hernández, A., Barra, R., Soto-Moyano, R., and Laurido, C. (2007). Effects of interleukin-1beta on spinal cord nociceptive transmission in intact and propentofylline-treated rats. Int. J. Neurosci. 117, 617-625. doi: 10.1080/00207450600773806

Badhiwala, J. H., Ahuja, C. S., and Fehlings, M. G. (2018a). Time is spine: a review of translational advances in spinal cord injury. J. Neurosurg. Spine 30, 1-18. doi: 10.3171/2018.9.spine18682

Badhiwala, J. H., Wilson, J. R., Kwon, B. K., Casha, S., and Fehlings, M. G. (2018b). A review of clinical trials in spinal cord injury including biomarkers. J. Neurotr. 35, 1906-1917.

Bedi, S. S., Yang, Q., Crook, R. J., Du, J., Wu, Z., Fishman, H. M., et al. (2010). Chronic spontaneous activity generated in the somata of primary nociceptors is associated with pain-related behavior after spinal cord injury. J. Neurosci. 30, 14870-14882. doi: 10.1523/jneurosci.2428-10.2010

Bellver-Landete, V., Bretheau, F., Mailhot, B., Vallières, N., Lessard, M., Janelle, M. E., et al. (2019). Microglia are an essential component of the neuroprotective scar that forms after spinal cord injury. Nat. Commun. 10:518.

Block, M. L., Zecca, L., and Hong, J.-S. (2007). Microglia-mediated neurotoxicity: uncovering the molecular mechanisms. Nat. Rev. Neurosci. 8, 57-69. doi: 10. 1038/nrn2038

Boadas-Vaello, P., Castany, S., Homs, J., Álvarez-Pérez, B., Deulofeu, M., and Verdú, E. (2016). Neuroplasticity of ascending and descending pathways after somatosensory system injury: reviewing knowledge to identify neuropathic pain therapeutic targets. Spinal Cord 54, 330-340. doi: 10.1038/sc.2015.225

Bourne, S., Machado, A. G., and Nagel, S. J. (2014). Basic anatomy and physiology of pain pathways. Neurosurg. Clin. N. Am. 25, 629-638. doi: 10.1016/j.nec.2014. 06.001

Braaf, S., Lennox, A., Nunn, A., and Gabbe, B. (2017). Social activity and relationship changes experienced by people with bowel and bladder dysfunction following spinal cord injury. Spinal Cord 55, 679-686. doi: 10.1038/sc.2017.19

Bradbury, E. J., and Burnside, E. R. (2019). Moving beyond the glial scar for spinal cord repair. Nat. Commun. 10, 3879-3879.

Braz, J. M., Etlin, A., Juarez-Salinas, D., Llewellyn-Smith, I. J., and Basbaum, A. I. (2017). Rebuilding CNS inhibitory circuits to control chronic neuropathic pain and itch. Progress Brain Res. 231, 87-105. doi: 10.1016/bs.pbr.2016.10.001

Bryce, T. N., Biering-Sørensen, F., Finnerup, N. B., Cardenas, D. D., Defrin, R., Lundeberg, T., et al. (2012). International spinal cord injury pain classification: part I. Background and description. March 6-7, 2009. Spinal Cord 50, 413-417. doi: $10.1038 /$ sc.2011.156

Burke, D., Fullen, B. M., Stokes, D., and Lennon, O. (2017). Neuropathic pain prevalence following spinal cord injury: a systematic review and meta-analysis. Eur. J. Pain 21, 29-44. doi: 10.1002/ejp. 905

Carlton, S. M., Du, J., Tan, H. Y., Nesic, O., Hargett, G. L., Bopp, A. C., et al. (2009). Peripheral and central sensitization in remote spinal cord regions contribute

\section{AUTHOR CONTRIBUTIONS}

SC wrote the first version of the manuscript and edited the subsequent versions. IT and CC corrected and edited the original manuscript and subsequent versions. All authors contributed to the article and approved the submitted version.

\section{FUNDING}

Funding came from Prémio Melo e Castro 2016 - Santa Casa da Misericórdia de Lisboa. SC was supported by Fundação para a Ciência e Tecnologia (Ph.D. Scholarship SFRH/BD/135868/2018).

to central neuropathic pain after spinal cord injury. Pain 147, 265-276. doi: 10.1016/j.pain.2009.09.030

Casha, S., Zygun, D., McGowan, M. D., Bains, I., Yong, V. W., and Hurlbert, R. J. (2012). Results of a phase II placebo-controlled randomized trial of minocycline in acute spinal cord injury. Brain 135, 1224-1236. doi: 10.1093/brain/aws072

Chen, G., Park, C. K., Xie, R. G., Berta, T., Nedergaard, M., and Ji, R. R. (2014). Connexin-43 induces chemokine release from spinal cord astrocytes to maintain late-phase neuropathic pain in mice. Brain 137, 2193-2209. doi: 10.1093/brain/awu140

Colburn, R. W., Rickman, A. J., and DeLeo, J. A. (1999). The effect of site and type of nerve injury on spinal glial activation and neuropathic pain behavior. Exp. Neurol. 157, 289-304. doi: 10.1006/exnr.1999.7065

Crown, E. D., Gwak, Y. S., Ye, Z., Johnson, K. M., and Hulsebosch, C. E. (2008). Activation of p38 MAP kinase is involved in central neuropathic pain following spinal cord injury. Exp. Neurol. 213, 257-267. doi: 10.1016/j.expneurol.2008. 05.025

Crown, E. D., Ye, Z., Johnson, K. M., Xu, G.-Y., McAdoo, D. J., and Hulsebosch, C. E. (2006). Increases in the activated forms of ERK 1/2, p38 MAPK, and CREB are correlated with the expression of at-level mechanical allodynia following spinal cord injury. Exp. Neurol. 199, 397-407. doi: 10.1016/j.expneurol.2006. 01.003

Deonarine, K., Panelli, M. C., Stashower, M. E., Jin, P., Smith, K., Slade, H. B., et al. (2007). Gene expression profiling of cutaneous wound healing. J. Transl. Med. $5,11-11$.

Detloff, M. R., Fisher, L. C., McGaughy, V., Longbrake, E. E., Popovich, P. G., and Basso, D. M. (2008). Remote activation of microglia and pro-inflammatory cytokines predict the onset and severity of below-level neuropathic pain after spinal cord injury in rats. Exp. Neurol. 212, 337-347. doi: 10.1016/j.expneurol. 2008.04.009

Didangelos, A., Puglia, M., Iberl, M., Sanchez-Bellot, C., Roschitzki, B., and Bradbury, E. J. (2016). High-throughput proteomics reveal alarmins as amplifiers of tissue pathology and inflammation after spinal cord injury. Sci. Rep. 6:21607.

Dijkers, M., Bryce, T., and Zanca, J. (2009). Prevalence of chronic pain after traumatic spinal cord injury: a systematic review. J. Rehabil. Res. Dev. 46, $13-29$.

Dusart, I., and Schwab, M. E. (1994). Secondary cell death and the inflammatory reaction after dorsal hemisection of the rat spinal cord. Eur. J. Neurosci. 6, 712-724. doi: 10.1111/j.1460-9568.1994.tb00983.x

Evaniew, N., Belley-Côté, E. P., Fallah, N., Noonan, V. K., Rivers, C. S., and Dvorak, M. F. (2016). Methylprednisolone for the treatment of patients with acute spinal cord injuries: a systematic review and meta-analysis. J. Neurotr. 33, 468-481. doi: 10.1089/neu.2015.4192

Fenton, B. W., Shih, E., and Zolton, J. (2015). The neurobiology of pain perception in normal and persistent pain. Pain Manag. 5, 297-317. doi: 10.2217/pmt.15.27

Finnerup, N. B. (2013). Pain in patients with spinal cord injury. Pain 154(Suppl. 1), S71-S76.

Garrison, C. J., Dougherty, P. M., Kajander, K. C., and Carlton, S. M. (1991). Staining of glial fibrillary acidic protein (GFAP) in lumbar spinal cord increases 
following a sciatic nerve constriction injury. Brain Res. 565, 1-7. doi: 10.1016/ 0006-8993(91)91729-k

Gensel, J. C., and Zhang, B. (2015). Macrophage activation and its role in repair and pathology after spinal cord injury. Brain Res. 1619, 1-11. doi: 10.1016/j. brainres.2014.12.045

Gwak, Y. S., Crown, E. D., Unabia, G. C., and Hulsebosch, C. E. (2008). Propentofylline attenuates allodynia, glial activation and modulates GABAergic tone after spinal cord injury in the rat. Pain 138, 410-422. doi: 10.1016/j.pain. 2008.01.021

Gwak, Y. S., and Hulsebosch, C. E. (2009). Remote astrocytic and microglial activation modulates neuronal hyperexcitability and below-level neuropathic pain after spinal injury in rat. Neuroscience 161, 895-903. doi: 10.1016/j. neuroscience.2009.03.055

Gwak, Y. S., Hulsebosch, C. E., and Leem, J. W. (2017). Neuronal-glial interactions maintain chronic neuropathic pain after spinal cord injury. Neural Plast. 2017:2480689.

Gwak, Y. S., Kang, J., Unabia, G. C., and Hulsebosch, C. E. (2012). Spatial and temporal activation of spinal glial cells: role of gliopathy in central neuropathic pain following spinal cord injury in rats. Exp. Neurol. 234, 362-372. doi: 10.1016/j.expneurol.2011.10.010

Gwak, Y. S., Unabia, G. C., and Hulsebosch, C. E. (2009). Activation of p-38alpha MAPK contributes to neuronal hyperexcitability in caudal regions remote from spinal cord injury. Exp. Neurol. 220, 154-161. doi: 10.1016/j.expneurol.2009. 08.012

Hains, B. C., Klein, J. P., Saab, C. Y., Craner, M. J., Black, J. A., and Waxman, S. G. (2003). Upregulation of sodium channel Nav1.3 and functional involvement in neuronal hyperexcitability associated with central neuropathic pain after spinal cord injury. J. Neurosci. 23, 8881-8892. doi: 10.1523/jneurosci.23-26-08881. 2003

Hains, B. C., and Waxman, S. G. (2006). Activated microglia contribute to the maintenance of chronic pain after spinal cord injury. J. Neurosci. 26, 4308-4317. doi: 10.1523/jneurosci.0003-06.2006

Heinricher, M. M., Tavares, I., Leith, J. L., and Lumb, B. M. (2009). Descending control of nociception: specificity, recruitment and plasticity. Brain Res. Rev. 60, 214-225. doi: 10.1016/j.brainresrev.2008.12.009

Hines, D. J., Hines, R. M., Mulligan, S. J., and Macvicar, B. A. (2009). Microglia processes block the spread of damage in the brain and require functional chloride channels. Glia 57, 1610-1618. doi: 10.1002/glia.20874

James, S. L., Theadom, A., Ellenbogen, R. G., Bannick, M. S., Montjoy-Venning, W., Lucchesi, L. R., et al. (2019). Global, regional, and national burden of traumatic brain injury and spinal cord injury, 1990-2016: a systematic analysis for the Global Burden of Disease Study 2016. Lancet Neurol. 18, 56-87.

Ji, R. R., Chamessian, A., and Zhang, Y. Q. (2016). Pain regulation by non-neuronal cells and inflammation. Science 354, 572-577. doi: 10.1126/science.aaf8924

Jones, T. B. (2014). Lymphocytes and autoimmunity after spinal cord injury. Exp. Neurol. 258, 78-90. doi: 10.1016/j.expneurol.2014.03.003

Junger, H., and Sorkin, L. S. (2000). Nociceptive and inflammatory effects of subcutaneous TNFalpha. Pain 85, 145-151. doi: 10.1016/s0304-3959(99) 00262-6

Kawasaki, Y., Zhang, L., Cheng, J.-K., and Ji, R.-R. (2008). Cytokine mechanisms of central sensitization: distinct and overlapping role of interleukin-1beta, interleukin-6, and tumor necrosis factor-alpha in regulating synaptic and neuronal activity in the superficial spinal cord. J. Neurosci. 28, 5189-5194. doi: 10.1523/jneurosci.3338-07.2008

Kigerl, K. A., Gensel, J. C., Ankeny, D. P., Alexander, J. K., Donnelly, D. J., and Popovich, P. G. (2009). Identification of two distinct macrophage subsets with divergent effects causing either neurotoxicity or regeneration in the injured mouse spinal cord. J. Neurosci. 29, 13435-13444. doi: 10.1523/jneurosci.325709.2009

Kjell, J., and Olson, L. (2016). Rat models of spinal cord injury: from pathology to potential therapies. Dis. Model Mech. 9, 1125-1137. doi: 10.1242/dmm.0 25833

Kramer, J. L. K., Minhas, N. K., Jutzeler, C. R., Erskine, E. L. K. S., Liu, L. J. W., and Ramer, M. S. (2017). Neuropathic pain following traumatic spinal cord injury: models, measurement, and mechanisms. J. Neurosci. Res. 95, 1295-1306. doi: $10.1002 /$ jnr.23881

Kwon, B. K., Curt, A., Belanger, L. M., Bernardo, A., Chan, D., Markez, J. A., et al. (2009). Intrathecal pressure monitoring and cerebrospinal fluid drainage in acute spinal cord injury: a prospective randomized trial. J. Neurosurg. Spine 10, 181-193. doi: 10.3171/2008.10.spine08217

Lee, S., Shi, X. Q., Fan, A., West, B., and Zhang, J. (2018). Targeting macrophage and microglia activation with colony stimulating factor 1 receptor inhibitor is an effective strategy to treat injury-triggered neuropathic pain. Mol. Pain 14:1744806918764979.

Lee-Kubli, C. A., Ingves, M., Henry, K. W., Shiao, R., Collyer, E., Tuszynski, M. H., et al. (2016). Analysis of the behavioral, cellular and molecular characteristics of pain in severe rodent spinal cord injury. Exp. Neurol. 278, 91-104. doi: 10.1016/j.expneurol.2016.01.009

Liddelow, S. A., Guttenplan, K. A., Clarke, L. E., Bennett, F. C., Bohlen, C. J., Schirmer, L., et al. (2017). Neurotoxic reactive astrocytes are induced by activated microglia. Nature 541, 481-487.

Loane, D. J., and Byrnes, K. R. (2010). Role of microglia in neurotrauma. Neurotherapeutics 7, 366-377. doi: 10.1016/j.nurt.2010. 07.002

Loeser, J. D., and Treede, R.-D. (2008). The Kyoto protocol of IASP basic pain terminology. Pain 137, 473-477. doi: 10.1016/j.pain.2008.04.025

Malcangio, M. (2019). Role of the immune system in neuropathic pain. Scand. J. Pain 20, 33-37. doi: 10.1515/sjpain-2019-0138

Marchand, F., Tsantoulas, C., Singh, D., Grist, J., Clark, A. K., Bradbury, E. J., et al. (2009). Effects of Etanercept and Minocycline in a rat model of spinal cord injury. Eur. J. Pain 13, 673-681. doi: 10.1016/j.ejpain.2008. 08.001

Martins, I., and Tavares, I. (2017). Reticular formation and pain: the past and the future. Front. Neuroanat. 11:51. doi: 10.3389/fnana.2017.00051

Monteiro, S., Salgado, A. J., and Silva, N. A. (2018). Immunomodulation as a neuroprotective strategy after spinal cord injury. Neural Regen. Res. 13, 423-424.

Nahrendorf, M., Swirski, F. K., Aikawa, E., Stangenberg, L., Wurdinger, T., Figueiredo, J.-L., et al. (2007). The healing myocardium sequentially mobilizes two monocyte subsets with divergent and complementary functions. J. Exp. Med. 204, 3037-3047. doi: 10.1084/jem.20070885

Neirinckx, V., Coste, C., Franzen, R., Gothot, A., Rogister, B., and Wislet, S. (2014). Neutrophil contribution to spinal cord injury and repair. J. Neuroinflamm. 11:150.

Noble, B. T., Brennan, F. H., and Popovich, P. G. (2018). The spleen as a neuroimmune interface after spinal cord injury. J. Neuroimmunol. 321, 1-11. doi: 10.1016/j.jneuroim.2018.05.007

Park, E., Velumian, A. A., and Fehlings, M. G. (2004). The role of excitotoxicity in secondary mechanisms of spinal cord injury: a review with an emphasis on the implications for white matter degeneration. J. Neurotr. 21, 754-774. doi: 10.1089/0897715041269641

Peng, X.-M., Zhou, Z.-G., Glorioso, J. C., Fink, D. J., and Mata, M. (2006). Tumor necrosis factor-alpha contributes to below-level neuropathic pain after spinal cord injury. Ann. Neurol. 59, 843-851. doi: 10.1002/ana.20855

Perkins, N. M., and Tracey, D. J. (2000). Hyperalgesia due to nerve injury: role of neutrophils. Neuroscience 101, 745-757. doi: 10.1016/s0306-4522(00)0 0396-1

Pineau, I., Sun, L., Bastien, D., and Lacroix, S. (2010). Astrocytes initiate inflammation in the injured mouse spinal cord by promoting the entry of neutrophils and inflammatory monocytes in an IL-1 receptor/MyD88dependent fashion. Brain Behav. Immun. 24, 540-553. doi: 10.1016/j.bbi.2009. 11.007

Popovich, P. G., and Hickey, W. F. (2001). Bone marrow chimeric rats reveal the unique distribution of resident and recruited macrophages in the contused rat spinal cord. J. Neuropathol. Exp. Neurol. 60, 676-685. doi: 10.1093/jnen/60.7. 676

Raghavendra, V., Tanga, F., and DeLeo, J. A. (2003). Inhibition of microglial activation attenuates the development but not existing hypersensitivity in a rat model of neuropathy. J. Pharmacol. Exp. Ther. 306, 624-630. doi: 10.1124/jpet. 103.052407

Roh, D.-H., Yoon, S.-Y., Seo, H.-S., Kang, S.-Y., Han, H.-J., Beitz, A. J., et al. (2010). Intrathecal injection of carbenoxolone, a gap junction decoupler, attenuates the induction of below-level neuropathic pain after spinal cord injury in rats. Exp. Neurol. 224, 123-132. doi: 10.1016/j.expneurol.2010.03.002

Rossignol, S., Schwab, M., Schwartz, M., and Fehlings, M. G. (2007). Spinal cord injury: time to move? J. Neurosci. 27, 11782-11792. 
Rust, R., and Kaiser, J. (2017). Insights into the dual role of inflammation after spinal cord injury. J. Neurosci. 37, 4658-4660. doi: 10.1523/jneurosci.0498-17. 2017

Schomberg, D., and Olson, J. K. (2012). Immune responses of microglia in the spinal cord: contribution to pain states. Exp. Neurol. 234, 262-270. doi: 10. 1016/j.expneurol.2011.12.021

Shechter, R., and Schwartz, M. (2013). CNS sterile injury: just another wound healing? Trends Mol. Med. 19, 135-143. doi: 10.1016/j.molmed.2012.11.007

Shiao, R., and Lee-Kubli, C. A. (2018). Neuropathic pain after spinal cord injury: challenges and research perspectives. Neurotherapeutics 15, 635-653. doi: 10 . 1007/s13311-018-0633-4

Shultz, R. B., and Zhong, Y. (2017). Minocycline targets multiple secondary injury mechanisms in traumatic spinal cord injury. Neural Regen. Res. 12, 702-713.

Siddall, P. J., McClelland, J. M., Rutkowski, S. B., and Cousins, M. J. (2003). A longitudinal study of the prevalence and characteristics of pain in the first 5 years following spinal cord injury. Pain 103, 249-257. doi: 10.1016/s03043959(02)00452-9

Silva, N. A., Sousa, N., Reis, R. L., and Salgado, A. J. (2014). From basics to clinical: a comprehensive review on spinal cord injury. Prog. Neurobiol. 114, 25-57. doi: 10.1016/j.pneurobio.2013.11.002

Sorkin, L. S., Xiao, W. H., Wagner, R., and Myers, R. R. (1997). Tumour necrosis factor-alpha induces ectopic activity in nociceptive primary afferent fibres. Neuroscience 81, 255-262. doi: 10.1016/s0306-4522(97)00147-4

Sroga, J. M., Jones, T. B., Kigerl, K. A., McGaughy, V. M., and Popovich, P. G. (2003). Rats and mice exhibit distinct inflammatory reactions after spinal cord injury. J. Comp. Neurol. 462, 223-240. doi: 10.1002/cne.10736

Stroman, P. W., Khan, H. S., Bosma, R. L., Cotoi, A. I., Leung, R., Cadotte, D. W., et al. (2016). Changes in pain processing in the spinal cord and brainstem after spinal cord injury characterized by functional magnetic resonance imaging. J. Neurotr. 33, 1450-1460. doi: 10.1089/neu.2015.4257

Tan, A. M., Zhao, P., Waxman, S. G., and Hains, B. C. (2009). Early microglial inhibition preemptively mitigates chronic pain development after experimental spinal cord injury. J. Rehabil. Res. Dev. 46, 123-133.

Tozaki-Saitoh, H., and Tsuda, M. (2019). Microglia-neuron interactions in the models of neuropathic pain. Biochem. Pharmacol. 169:113614. doi: 10.1016/ j.bcp.2019.08.016

Tran, A. P., Warren, P. M., and Silver, J. (2018). The biology of regeneration failure and success after spinal cord injury. Physiol. Rev. 98, 881-917. doi: 10.1152/physrev.00017.2017

Ulndreaj, A., Chio, J. C., Ahuja, C. S., and Fehlings, M. G. (2016). Modulating the immune response in spinal cord injury. Expert. Rev. Neurother. 16, 1127-1129. doi: 10.1080/14737175.2016.1207532
Vilhardt, F. (2005). Microglia: phagocyte and glia cell. Int. J. Biochem. Cell Biol. 37, 17-21. doi: 10.1016/j.biocel.2004.06.010

Wagner, R., and Myers, R. R. (1996). Schwann cells produce tumor necrosis factor alpha: expression in injured and non-injured nerves. Neuroscience 73, 625-629. doi: 10.1016/0306-4522(96)00127-3

Widerström-Noga, E. (2017). Neuropathic pain and spinal cord injury: phenotypes and pharmacological management. Drugs 77, 967-984. doi: 10.1007/s40265017-0747-8

Xu, K., Malouf, A. T., Messing, A., and Silver, J. (1999). Glial fibrillary acidic protein is necessary for mature astrocytes to react to beta-amyloid. Glia 25, 390-403. doi: 10.1002/(sici)1098-1136(19990215)25:4<390::aid-glia8>3.0. co;2-7

Yang, D., Han, Z., and Oppenheim, J. J. (2017). Alarmins and immunity. Immunol. Rev. 280, 41-56. doi: 10.1111/imr.12577

Yang, Q., Wu, Z., Hadden, J. K., Odem, M. A., Zuo, Y., Crook, R. J., et al. (2014). Persistent pain after spinal cord injury is maintained by primary afferent activity. J. Neurosci. 34, 10765-10769. doi: 10.1523/jneurosci.5316-13.2014

Zai, L. J., and Wrathall, J. R. (2005). Cell proliferation and replacement following contusive spinal cord injury. Glia 50, 247-257. doi: 10.1002/glia.20176

Zhang, Z.-J., Jiang, B.-C., and Gao, Y.-J. (2017). Chemokines in neuron-glial cell interaction and pathogenesis of neuropathic pain. Cell Mol. Life Sci. 74, 3275-3291. doi: 10.1007/s00018-017-2513-1

Zhou, X., Wahane, S., Friedl, M. S., Kluge, M., Friedel, C. C., Avrampou, K., et al. (2020). Microglia and macrophages promote corralling, wound compaction and recovery after spinal cord injury via Plexin-B2. Nat. Neurosci. 23, 337-350. doi: 10.1038/s41593-020-0597-7

Zhuang, Z.-Y., Gerner, P., Woolf, C. J., and Ji, R.-R. (2005). ERK is sequentially activated in neurons, microglia, and astrocytes by spinal nerve ligation and contributes to mechanical allodynia in this neuropathic pain model. Pain 114, 149-159. doi: 10.1016/j.pain.2004.12.022

Conflict of Interest: The authors declare that the research was conducted in the absence of any commercial or financial relationships that could be construed as a potential conflict of interest.

Copyright (c) 2020 Chambel, Tavares and Cruz. This is an open-access article distributed under the terms of the Creative Commons Attribution License (CC BY). The use, distribution or reproduction in other forums is permitted, provided the original author(s) and the copyright owner(s) are credited and that the original publication in this journal is cited, in accordance with accepted academic practice. No use, distribution or reproduction is permitted which does not comply with these terms. 